\title{
Ultrastructural Changes During Sporulation of Clostridium bifermentans
}

\author{
By K. JOHNSTONE* AND K. T. HOLLAND \\ Department of Microbiology, School of Medicine, Leeds LS2 9 NL
}

(Received I3 January 1977)

INTRODUCTION

The sporulation events in several members of the genus Bacillus have been extensively studied and may be divided into seven stages (Murrell, 1967). The sporulation events in members of the genus Clostridium are essentially the same as in the genus Bacillus (FitzJames \& Young, 1969; Walker, 1970), but minor differences exist between the two genera, between species of the same genus and between strains of the same species. In some clostridia, for example Clostridium pectinovorum, the coats appear as discontinuous masses which link together to form continuous layers (Fitz-James, 1962), whereas in the genus Bacillus the coats usually appear as continuous layers. A recent study of Clostridium pasteurianum (Mackey \& Morris, 197I) has shown that coat production precedes cortex development, which is the reverse of the sequence in C. pectinovorum and in the bacilli. Walker, Thompson \& Baillie (1967) showed that the sporulation events in Clostridium bifermentans strain CNI6I 7 were essentially the same as those in C.pectinovorum (Fitz-James, 1962), the coats being formed externally to the developing cortex and apparently flexible in the early stages. In a more recent study of spore appendage development in C. bifermentans strain UK-AI003 (Samsonoff, Hashimoto \& Conti, I97I), coat formation occurred before cortex development, the coats being formed by the linking up of electron-dense fragments of material with little suggestion of coat flexibility.

The present study was undertaken to clarify the sporulation events in a strain of $C$. bifermentans in which rapid vegetative growth and equally rapid, reasonably synchronous sporulation could readily be induced, making it potentially useful for the study of sporulation in the anaerobes.

\section{METHODS}

Organism. Clostridium bifermentans strain M86b was maintained in Robertson's cooked meat broth.

Sporulation system. A flask containing $700 \mathrm{ml} 3 \%(\mathrm{w} / \mathrm{v})$ tryptone (Oxoid L 42) and I \% (w/v) yeast extract (Oxoid L 2I) at pH 7.0, was autoclaved at $\mathrm{I}_{2 \mathrm{I}}{ }^{\circ} \mathrm{C}$ for $20 \mathrm{~min}$. This medium, at $37^{\circ} \mathrm{C}$, was stirred, sparged with oxygen-free nitrogen and inoculated with a $12 \mathrm{~h}$ culture of $C$. bifermentans grown in the same medium.

Measurement of growth and estimation of sporulation. Nephelometer readings were taken on Io $\mathrm{ml}$ culture samples using an EEL nephelometer, and formation of phase-bright forespores was followed by examination of samples under a Nikon phase-contrast microscope.

Electron microscopy. Culture samples $(9 \mathrm{ml})$ were taken at $10 \mathrm{~min}$ intervals during sporulation, fixed with osmium tetroxide and prestained with uranyl acetate (Kellenberger,

*Present address: Department of Biochemistry, University of Cambridge, Cambridge CB2 IQW. 
Ryter \& Séchaud, I958). Resuspension of the pellet of fixed organisms was modified as follows to facilitate preparation of the agar blocks. The pellet was resuspended in $0.02 \mathrm{ml}$ $2 \%$ (w/v) agar at $45^{\circ} \mathrm{C}$, and a column of the suspension was drawn into a Pasteur pipette with an internal diameter of approximately $\mathrm{I} \mathrm{mm}$. The solidified gel was extruded on to a microscope slide and $\mathrm{I} \mathrm{mm}$ cylinders cut from it and placed in the uranyl acetate washing fluid of Kellenberger et al. (1958). The cylinders were dehydrated in ethanol, transferred to acetone and embedded in Epon (Luft, I96I). After polymerization by heating at $60^{\circ} \mathrm{C}$ for $24 \mathrm{~h}$, sections approximately $80 \mathrm{~nm}$ thick were cut on an LKB Ultratome microtome using glass knives, were picked up on 400-mesh copper grids and examined without further staining in a Philips EM 300 electron microscope, using an accelerating voltage of $60 \mathrm{kV}$ and an objective aperture of $30 \mu \mathrm{m}$.

\section{RESULTS AND DISCUSSION}

Exponential growth of $C$. bifermentans was rapid, with a doubling time of II 9 min from the nephelometer readings. Formation of phase-bright forespores was the first sign of sporulation; these were formed within $\mathrm{I} h$ by over $95 \%$ of the population.

The onset of sporulation occurred during the initial fall-off in vegetative growth as observed by nephelometry. This is consistent with the theory that sporulation occurs at the end of the exponential growth phase when the generation time increases due to limitation of an essential nutrient (Vinter, 1969). Axial filament formation was rarely observed during sporulation of this organism, was not mentioned in the study of $C$. bifermentans by Walker et al. (1967) and was only rarely observed in C. pasteurianum (Mackey \& Morris, 1971). These observations suggest that axial filament formation is not a necessary prelude to sporulation. The first sign of sporulation in C. bifermentans was the formation of the forespore septum, approximately one-quarter of the way along the vegetative cell, which isolated a portion of nuclear material. This septum appeared to contain a narrow band of electrondense material continuous with the wall, suggesting that during formation of the forespore septum, transverse wall synthesis, which occurs in the vegetatively dividing cell at the same time as transverse membrane synthesis in this organism, is not fully repressed. This band, if it is wall material, may be modified and incorporated into the cortex which subsequently develops between the inner and outer forespore membranes, and which contains peptidoglycan structurally distinct from that of the vegetative wall (Tipper \& Gauthier, 1972). Thus forespore septum synthesis represents the first visible sign of sporulation in this organism, appearing as a modified cell division (Hitchins \& Slepecky, I969).

As the forespore was engulfed by the mother cell membrane, electron-transparent globules (Fig. I $a$ ) appeared in the cell cytoplasm but not within the forespore. Similar globules have been observed during sporulation of other bacteria and are thought to consist of glycogen (granulose), but may not exist as such in vivo, possibly being due to the aggregation of material during fixation. These globules, which indicate some phase-specific change in the mother cell cytoplasm during sporulation, disappeared at approximately the same time as the developing spore protoplast changed from being electron dense to electron lucent (Fig. I $a, b$ ). This suggests that these globules may be utilized during this transformation, possibly providing the energy for the process. When the forespore became totally engulfed, it moved slightly nearer to the middle of the cell and the electron-dense band between the inner and outer forespore membranes, where the cortex would develop, became more evident (Fig. I $a, b$ ). The coats were deposited as continuous layers (Fig. I $a, b, c$ ) as they are in several members of the genus Bacillus, rather than by the linking up of preformed 

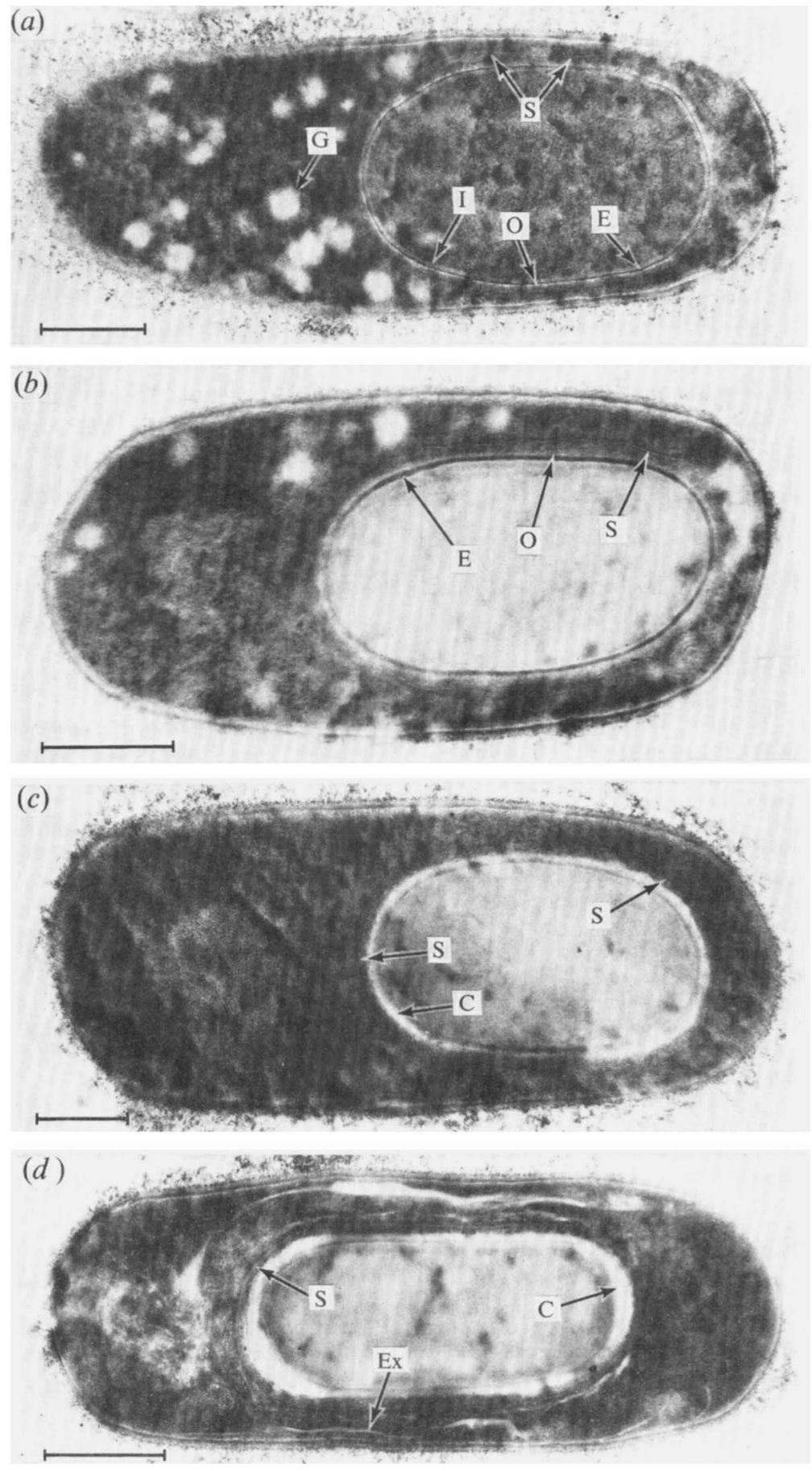

Fig. I. Electron micrographs of sections of sporulating C. bifermentans strain M86b. (a) Completion of forespore engulfment, with inner and outer membranes enclosing an electron-dense band, and deposition of the first spore coat. (b) Completed transition of forespore from electron-dense to electron-lucent appearance. $(c)$ Completion of deposition of two spore coats and start of cortex development. (d) Longitudinal section through a maturing spore within the mother cell. C, spore cortex; E, electron-dense band; Ex, exosporium; G, electron-transparent globule; I, inner forespore membrane; O, outer forespore membrane; S, spore coat(s). Bar markers represent $300 \mathrm{~nm}$. 
material as observed in C. pasteurianum (Mackey \& Morris, I97I) and C. pectinovorum (Fitz-James, 1962). The coats were apparently flexible in the early stages of spore formation, as observed by Walker et al. (1967) in C. bifermentans. The electron-dense band between the inner and outer forespore membranes developed into an electron-transparent cortex after the deposition of some of the coats (Fig. I $b, c, d$ ). Cortex development after coat deposition has also been observed in C. pasteurianum (Mackey \& Morris, I97I) whereas in other clostridia and in the bacilli it was considered to occur before coat deposition (Fitz-James \& Young, 1969). The presence of undulating coats before, and more regularly elliptical coats after, cortex development could support an expanded cortex theory (Gould \& Dring, 1974). For an expanded cortex to be formed, the coats would have to be deposited externally to the cortex before expansion occurred, so that such expansion could be limited, and to produce tightly fitting coats. Alternatively, the stretching of the coats could be due to accumulation of material between the inner and outer forespore membranes. The mature spore usually had four coats but as many as seven were occasionally seen. No spore appendages were observed in this strain of $C$. bifermentans but, in common with most other strains (Rode \& Smith, 197I), an exosporium was present which apparently consisted of two layers (Fig. I $d$ ).

\section{REFERENCES}

Fitz-JAmes, P. C. (1962). Morphology of spore development in Clostridium pectinovorum. Journal of Bacteriology 84, I04-II 4.

Fitz-James, P. C. \& Young, I. E. (I969). Morphology of sporulation. In The Bacterial Spore, pp. 39-72. Edited by G. W. Gould and A. Hurst. London: Academic Press.

Gould, G. W. \& Dring, G. J. (1974). Mechanisms of spore heat resistance. In Advances in Microbial Physiology, vol. I I, pp. 137-I64. Edited by A. H. Rose and D. W. Tempest. London: Academic Press.

Hitchins, A. D. \& Slepecky, R. A. (1969). Bacterial sporulation as a modified prokaryotic cell division. Nature, London 223, 804-807.

Kellenberger, E., RYTer, A. \& Séchaud, J. (1958). Electron microscopic study of DNA-containing plasms. II. Vegetative and mature phage DNA as compared with normal bacterial nucleoids in different physiological states. Journal of Biophysical and Biochemical Cytology 4, 671-678.

LUFT, J. H. (196I). Improvements in epoxy-resin embedding methods. Journal of Biophysical and Biochemical Cytology 9, 409-414.

MACKEY, B. M. \& Morris, J. G. (I971). Ultrastructural changes during sporulation of Clostridium pasteurianum. Journal of General Microbiology 66, $1-13$.

Murrell, W. G. (1967). The biochemistry of the bacterial endospore. In Advances in Microbial Physiology, vol. I, pp. 133-25I. Edited by A. H. Rose and J. F. Wilkinson. London: Academic Press.

Rode, L. J. \& SMITH, L. DS. (I97I). Taxonomic implications of spore fine structure in Clostridium bifermentans. Journal of Bacteriology ro5, 349-354.

Samsonoff, W. A., Hashimoto, T. \& ConTI, S. F. (1971). Appendage development in Clostridium bifermentans. Journal of Bacteriology ro6, 269-275.

Tipper, D. J. \& GaUtHiER, J. J. (1972). Structure of the bacterial endospore. In Spores V, pp. 3-I2. Edited by H. O. Halvorson, R. Hanson and L. L. Campbell. Washington, D.C.: American Society for Microbiology.

VinTER, V. (1969). Physiology and biochemistry of sporulation. In The Bacterial Spore, pp. 73-I23. Edited by G. W. Gould and A. Hurst. London: Academic Press.

WALKER, P. D. (1970). Cytology of spore formation and germination. Journal of Applied Bacteriology 33 , I $\rightarrow$ I 2 .

Walker, P. D., Thompson, R. O. \& BaIllie, A. (1967). Fine structure of clostridia with special reference to the location of their antigens and enzymes. Journal of Applied Bacteriology 30, 444-449. 